\title{
PBL-SYS: UM PROTÓTIPO DE UM AMBIENTE VIRTUAL DE APRENDIZAGEM PARA APOIAR A APRENDIZAGEM BASEADA EM PROBLEMAS (PBL - PROBLEM-BASED LEARNING)
}

\author{
Sidnei de Oliveira Sousa, Marcelo Vinícius Creres Rosa, Gunnar Correa Pereira Ferreira
}

Universidade do Oeste Paulista - UNOESTE, Faculdade de Informática de Presidente Prudente - FIPP, Presidente Prudente, SP. E-mail: siamf@ig.com.br

\section{RESUMO}

Esta pesquisa, em desenvolvimento, busca apresentar o PBL-SYS, um protótipo de um Ambiente Virtual de Aprendizagem (AVA) para a metodologia educacional da Aprendizagem Baseada em Problemas ( $\mathrm{PBL}$ - Problem-Based Learning). Para tanto, foi realizado um estudo de caráter qualitativo focando uma experiência na qual o PBL-SYS, foi estudado em suas diferentes manifestações como fonte de conhecimento. No que se refere ao levantamento de dados, este estudo fez uso da técnica da observação participante, uma vez que esta técnica permite a intervenção do pesquisador no objeto em estudo a partir da reflexão sobre os estímulos empregados. A análise dos dados evidenciou que o AVA utilizado para apoiar o processo do PBL deve atender ao design educacional de uma metodologia ativa. Assim, consideramos que os recursos técnicos e de comunicação presentes em um AVA dessa natureza devem ser projetados e desenvolvidos em concordância com as atividades específicas do PBL ou outra metodologia ativa.

Palavras-chave: Aprendizagem Baseada em Problemas, Ambiente Virtual de Aprendizagem, PBLSYS.

\section{PBL-SYS: A PROTOTYPE OF A VIRTUAL LEARNING ENVIRONMENT TO SUPPORT PROBLEM-BASED LEARNING}

\begin{abstract}
This research, in progress, seeks to present the PBL-SYS, a prototype of a Virtual Learning Environment (VLE) for the educational methodology of Problem-Based Learning (PBL - ProblemBased Learning). Therefore, we conducted a qualitative study focusing on an experiment in which the PBL-SYS was studied as a source of knowledge. With regard to data collection, this study made use of participant observation technique, since this technique allows the intervention of the researcher in the object under study from the reflection on the employees stimuli. Data analysis showed that the AVA used to support the process of PBL should meet the educational design of an active methodology. Thus, we consider that the technical and communication resources present in a VLE such should be devised and developed in accordance with the specific activities of PBL or other active methodology.

Keywords: Problem-Based Learning, Virtual Learning Environment, PBL-SYS.
\end{abstract}




\section{INTRODUÇÃO}

Embora muitas instituições estejam se voltando para a educação online, transferindo o paradigma do ensino tradicional para os Ambientes Virtuais de Aprendizagem (AVA), a estratégia metodológica da Aprendizagem Baseada em Problemas, ou, em idioma inglês Problem-Based Learning (PBL) parece encontrar dificuldades em migrar para esta modalidade. Há um número limitado de referências ao uso do PBL em ambientes na web, ou seja, os recursos online como fóruns de discussão, salas de bate-papo, entre outros, não estão sendo explorados para potencializar a metodologia PBL (BRODIE, 2006). A pouca propagação de iniciativas educacionais que articulem o PBL com recursos online faz com que qualquer experiência nesse sentido tenha um caráter bastante inovador, mas também bastante arriscado. Dessa forma, o desenvolvimento de estudos nessa área é realizado por Instituições comprometidas com uma educação de vanguarda, voltada para a divulgação de conhecimentos para alunos altamente influenciados por uma nova cultura de mídia digital.

Assim, uma proposta como esta, que visa investigar as implicações pedagógicas e técnicas para o desenvolvimento de um Ambiente Virtual de Aprendizagem (AVA) específico para o PBL, deve ser precedida por uma reflexão inicial sobre a razão de existir um AVA destinado unicamente a apoiar as atividades do PBL. Em cursos que utilizam metodologias ativas, é frequente o uso, ou adequação do mesmo AVA utilizado em metodologias convencionais de ensino, porém a filosofia educacional inerente aos AVAs convencionais é bastante diferente da filosofia que ampara as metodologias ativas, sobretudo o PBL. Logo, o uso de um AVA convencional em um curso que utiliza o PBL não atende aos pressupostos filosóficos e características definidoras do PBL, uma vez que possuem diferentes concepções epistemológicas.

Em primeiro lugar, a natureza de muitos dos métodos atuais de ensino e aprendizagem derivam das universidades medievais e, além de serem amplamente utilizados no ensino presencial, são estendidos também para um Ambiente Virtual de Aprendizagem (AVA) que possa vir a auxiliar nas aulas presenciais. Embora o uso da internet e de outros meios de comunicação sejam empregados na educação sob a égide de um discurso progressista, os métodos pedagógicos utilizados permanecem extremamente conservadores. A intenção não é, de forma alguma, depreciar os métodos do ensino convencional usados nos Ambientes Virtuais de Aprendizagem, mas propor uma alternativa para os cursos que, visando utilizar um AVA para apoiar metodologias ativas, não reproduzam a educação bancária, encontrada largamente no ensino presencial e tão contestada por Paulo Freire (1996) em suas pesquisas. Desse modo, começa a ser hora de 
perguntarmos se os métodos e os recursos empregados nos AVAs continuam sendo válidos no contexto contemporâneo para subsidiar atividades desenvolvidas em metodologias como o PBL.

Segundo Moraes (2002), os recursos pedagógicos que permeiam muitos AVAs são desenvolvidos essencialmente para apoiar a educação convencional, enfatizando a memorização de fatos ou de informações isoladas. Nesses casos, a profusão de tecnologias aplicadas ao AVA é responsável por camuflar velhas teorias que continuam concebendo o aluno como mero espectador. Embora muitos AVAs utilizem vastos recursos sonoros, visuais e de animações, carecem de recursos mais adequados e epistemologicamente mais atualizados com as metodologias ativas de ensino e aprendizagem.

Portanto, se faz premente a necessidade de lançarmos um olhar mais cuidadoso para o design educacional presente nos AVAs a fim de viabilizarmos práticas mais apropriadas para apoiar as atividades do PBL. Este trabalho apresenta uma proposta para o desenvolvimento de um Ambiente Virtual de Aprendizagem para apoiar atividades presenciais e a distância no processo de resolução de problemas, com a finalidade de refletir de maneira mais fiel a filosofia inerente à metodologia PBL e contribuir mais ativamente para o processo de construção do conhecimento.

Assim, este estudo destina-se a desenvolver e avaliar um Ambiente Virtual de Aprendizagem que ofereça suporte para as atividades educacionais realizadas segundo a estratégia da Aprendizagem Baseada em Problemas (Problem Based Learning - PBL).

\section{METODOLOGIA}

A busca por uma compreensão das implicações para o desenvolvimento e implantação de um Ambiente Virtual de Aprendizagem, no qual o PBL é a estratégia educacional, nos levou a optar por uma abordagem metodológica que se preocupasse com o contexto e com a forma pela qual este contexto influencia as várias variáveis de uma pesquisa. Por esse motivo, a abordagem qualitativa foi escolhida para nortear este estudo, uma vez que as ações são mais bem compreendidas no ambiente natural em que ocorrem (BOGDAN; BIKLEN, 1994). Além disso, a abordagem qualitativa é descritiva, ou seja, tudo que faz parte do contexto pode ser descrito e oferecer elementos para esclarecer pontos do objeto de estudo (BOGDAN; BIKLEN, 1994). A finalidade da descrição é atuar como auxiliar para o reconhecimento, assim, uma boa descrição é reconhecida em termos de facilidade para o leitor reconhecer o objeto. É este seu principal mérito: criar uma reprodução tão clara quanto possível do objeto de estudo (MARTINS, 2008).

É importante destacar que a pesquisa experimental foi escolhida como metodologia neste estudo, uma vez que toma o próprio objeto em sua concretude como fonte e o coloca em 
condições técnicas de observação (SEVERINO, 2007). Cumpre ressaltar que o objeto em questão é o processo de desenvolvimento de um AVA específico para a metodologia ativa PBL, denominado PBL-SYS, que foi alvo de uma manipulação experimental em condições adequadas para seu tratamento. A pesquisa experimental foi realizada em laboratórios de informática, no caso desta pesquisa, o laboratório para desenvolvimento de software de uma Universidade, onde se fez uso de técnicas e métodos para criar condições adequadas para o tratamento do objeto, foco do experimento. Nesse sentido, Michaliszyn e Tomasini (2007, p. 51) chamam a atenção para o controle das variáveis estabelecido pelo pesquisador na condução do seu estudo, uma vez que, “Delimitado o objeto de estudo, seleciona as variáveis que podem influenciá-lo, define formas de controle e de observação dos efeitos que a variável produz no objeto. Por outras palavras, trata-se da pesquisa desenvolvida a partir da observação direta dos fatos".

No tocante ao levantamento de dados, este estudo fez uso da técnica da observação participante, uma vez que essa técnica permite uma participação intensa do pesquisador no controle e análise das variáveis técnicas e pedagógicas do objeto em estudo, observando suas reações aos estímulos e suas formas de adaptação (MICHALISZYN; TOMASINI, 2007). A observação possibilitou que as implicações técnicas e pedagógicas fossem registradas durante o processo de desenvolvimento e testes do AVA (ALVES-MAZZOTTI; GEWANDSZNAJDER, 1999; LAKATOS; MARCONI, 1985). A observação representa a técnica mais eficiente para a coleta de dados quando o foco de estudo é um contexto específico, já que permite ao pesquisador uma observação detalhada e a identificação dos diferentes processos que interagem no contexto estudado (BOGDAN; BIKLEN, 1994).

\section{RESULTADOS}

O PBL-SYS é dividido em três módulos, Administrador, Professor e Aluno. Neste artigo, nos deteremos na descrição do módulo do aluno. No módulo do aluno são exibidas, ao centro da página, algumas opções referentes ao processo de resolução do problema no PBL (Figura 1). Ao acessar a opção Problema, o aluno pode realizar a leitura da situação-problema cadastrada pelo tutor. A opção Quadro Referencial permite que os alunos interajam para construir o quadro referente ao processo de resolução da situação-problema, o quadro permite o registro de ideias, fatos, questões de aprendizagem e estratégias de ação. A opção Fórum possibilita que os alunos colaborarem entre si com um nível maior de profundidade nas discussões. Por fim, na opção Solução o aluno enviará o(s) arquivo(s) referente(s) ao projeto de solução que o grupo encontrou, além disso, ainda na opção Solução o aluno deverá responder a um questionário de autoavaliação 
de seu desempenho no processo de resolução de problemas na metodologia PBL. É importante salientar que o AVA tem o recurso de mostrar quais integrantes do grupo estão online no AVA, potencializando a comunicação entre os alunos.

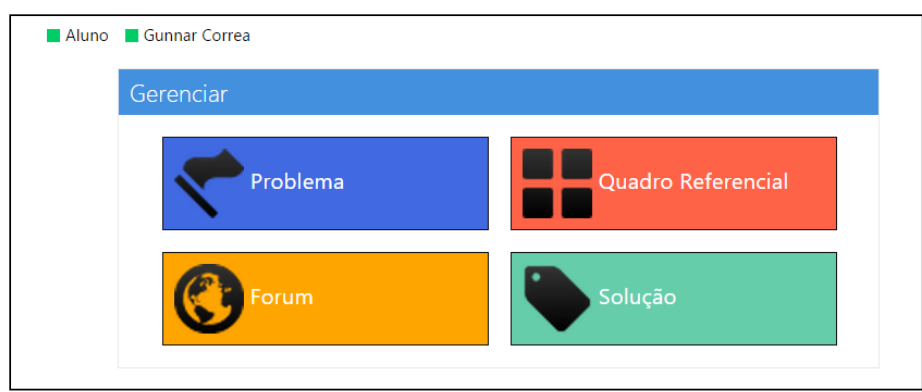

Figura 1. Tela de abertura do módulo do aluno.

Fonte: Os Autores.

Assim que o professor escreve a situação-problema no PBL-SYS, ele tem a opção de deixála visível aos alunos no momento que considerá-la adequada à leitura. A situação-problema é apresentada ao aluno na forma de texto quando ele clica na opção Problema disponível em seu módulo. É importante salientar que assim que o professor libera a situação-problema para leitura, todos os alunos recebem uma notificação por e-mail indicando que o texto do problema está online no AVA.

O Quadro Referencial online (Figura 2) é o recurso mais interativo do PBL-SYS no que se refere à resolução do problema mediante a colaboração entre os membros do grupo. No Quadro Referencial os alunos podem cadastrar suas ideias, fatos do problema, questões de aprendizagem e estratégias de ação (metas). Ao publicar um texto em um dos quadros, a publicação fica imediatamente disponível para todo o grupo com a indicação do aluno que a enviou. Ao lado direito do Quadro Referencial é possível ter acesso ao Chat (bate papo) do AVA. O Chat, na mesma página dos quadros, permite que as discussões sobre o processo de resolução do problema sejam realizadas de forma síncrona. 


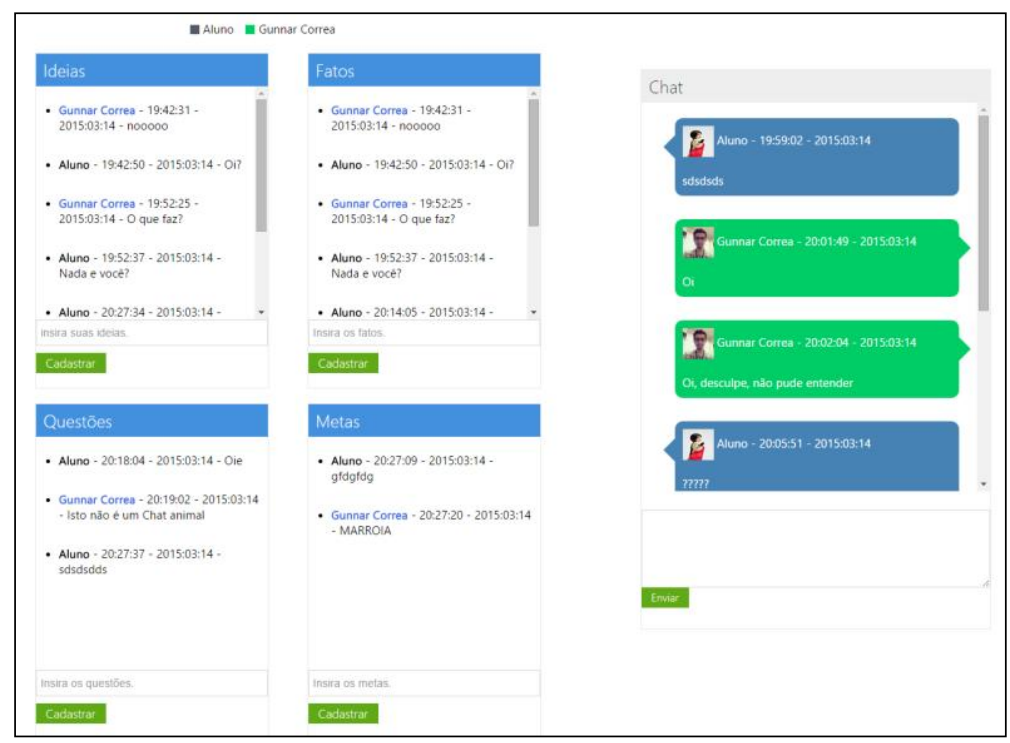

Figura 2 .Quadro Referencial Online.

Fonte: Os Autores.

Em todas as páginas do PBL-SYS é possível observar quem são os integrantes do grupo que estão online no AVA. A exibição dos alunos online é em tempo real, quando um aluno acessa o sistema (efetua o login) apenas os integrantes do seu grupo, já logados no sistema, conseguem ver o nome do aluno no topo da página marcado com a cor verde (Figura 3).

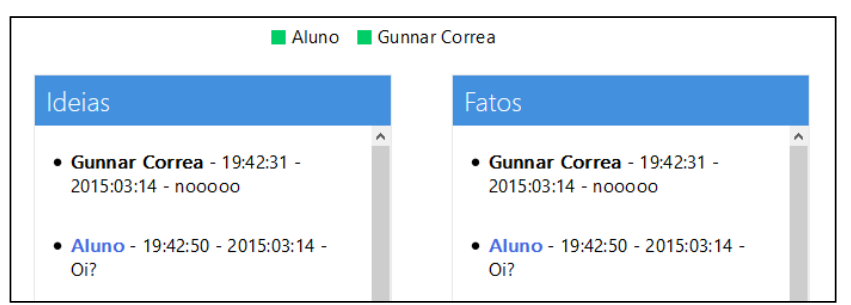

Figura 3. Exibição dos alunos online.

Fonte: Os Autores.

No que se refere ao uso do Fórum, assim que o aluno acessar o menu fórum, é exibido para ele todos os fóruns de discussão abertos pelo professor, como podemos observar na Figura 4 é apresentado o título do que se refere o fórum, a turma em que o aluno está cadastrado e um ícone de um olho verde aberto que significa que o fórum está aberto para discussões.

\begin{tabular}{|llc|}
\hline Listar Fórum & & \\
Titulo & Turma & \\
\hline Teste & A & 0 \\
Lista de interasăa & A & 0 \\
\hline
\end{tabular}

Figura 4. Lista de Fóruns criados pelo professor.

Fonte: Os Autores. 
Ao clicar no ícone do olho aberto, o aluno é direcionado para a página de discussão do fórum (Figura 5), onde ele pode deixar seus comentários a respeito de um assunto e discutir com outros colegas.

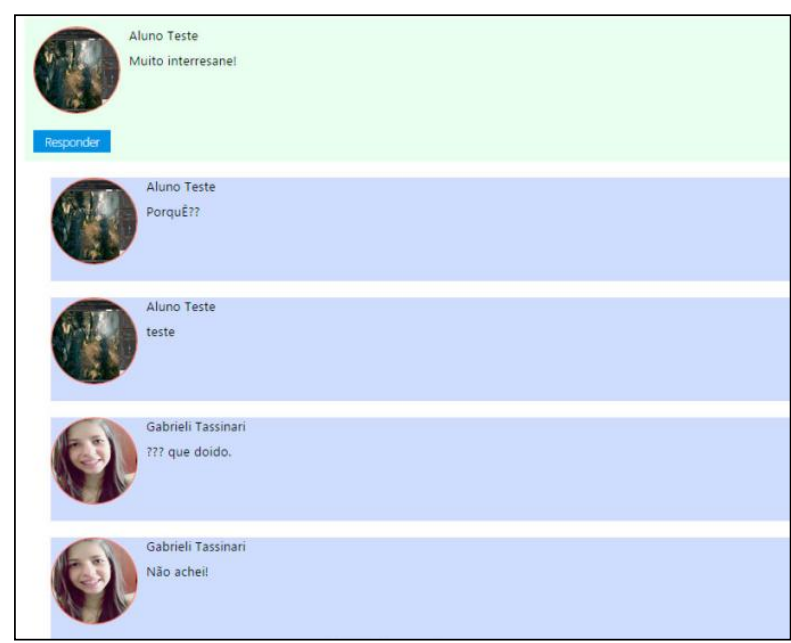

Figura 5. Interação dos alunos no fórum.

Fonte: Os Autores.

Após as discussões no Chat do Quadro Referencial Online e no Fórum, os alunos desenvolvem o projeto que visa resolver o problema proposto a eles. A opção Solução permite que o projeto desenvolvido pelo grupo seja enviado ao PBL-SYS para posterior análise do professor (Figura 6).

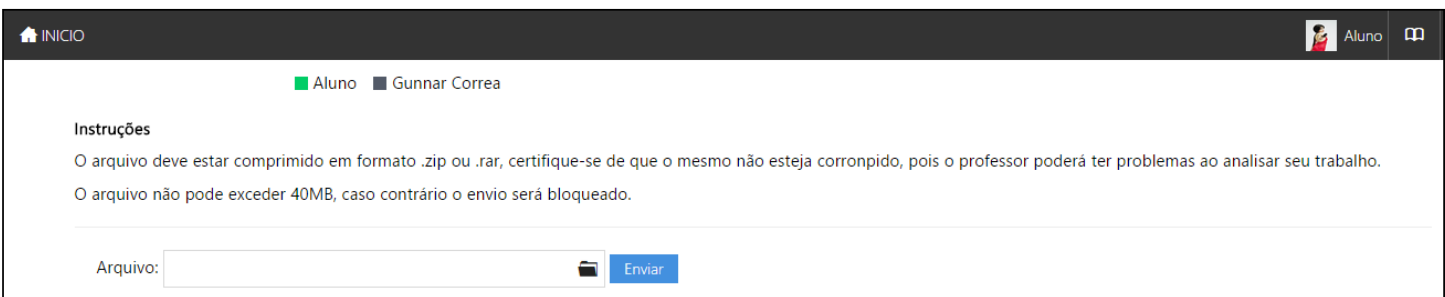

Figura 6. Exibição dos alunos online.

Fonte: Os Autores.

Por fim, ainda na opção Solução, o aluno deve responder a um questionário de autoavaliação de desempenho no processo de resolução de problemas (Figura 7). 


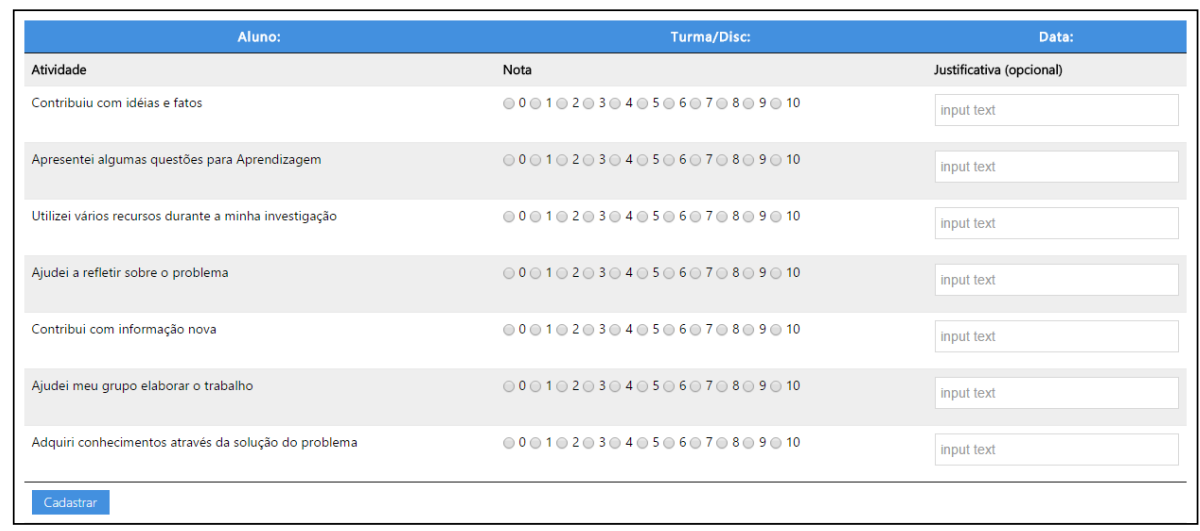

Figura 7. Questionário de autoavaliação.

Fonte: Os Autores.

Embora o foco dos resultados apresentados nesta pesquisa seja o módulo do aluno, é interessante apresentar um recurso que o PBL-SYS disponibiliza para o módulo do professor. Esse recurso é chamado de "Lista de Interação", por meio dele, o professor pode visualizar as interações entre os alunos de um determinado grupo nas diferentes ferramentas de comunicação disponibilizadas pelo PBL-SYS (Chat, Quadro Referencial e Fórum). Na Figura 8, podemos observar que o professor clicou na lista de interações do Fórum de Discussão, na qual ele pode observar que a primeira coluna corresponde a um aluno do grupo e as colunas representadas na cor verde indicam os outros alunos com os quais ele interagiu, além disso, o sistema marca com a cor vermelha a falta de interação do aluno com algum outro integrante do grupo.

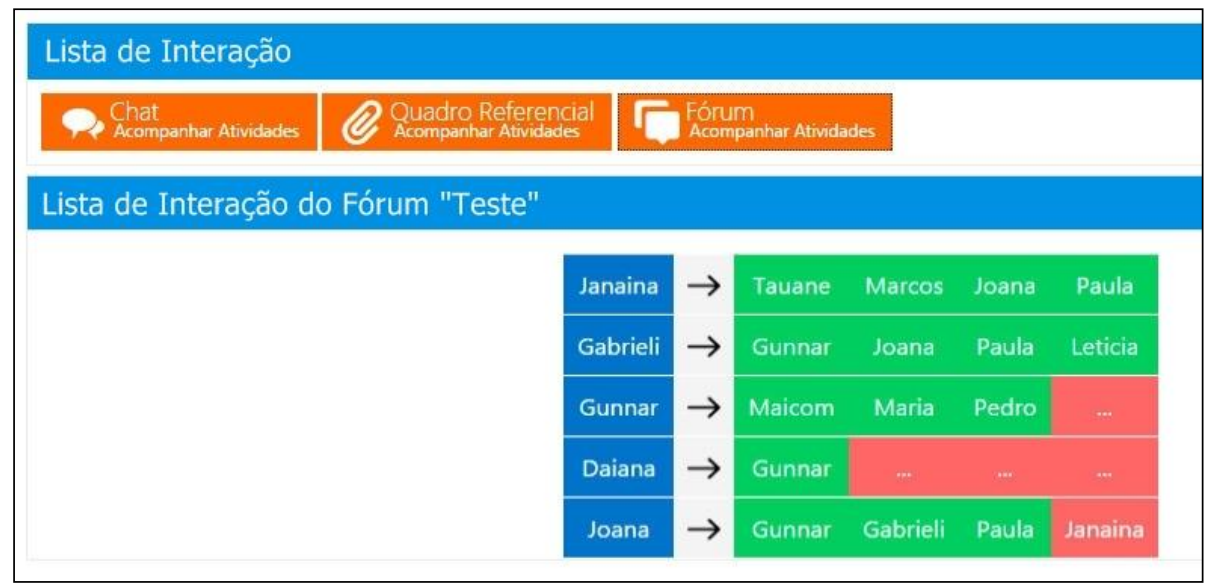

Figura 8. Lista de Interação dos alunos em um determinado Fórum.

Fonte: Os Autores.

\section{DISCUSSÃO}

Esta pesquisa enfatizou a necessidade de estudar as implicações técnicas e pedagógicas para o desenvolvimento de um AVA específico para auxiliar nos passos já clássicos da Aprendizagem Baseada em Problemas. Nesse sentido, podemos considerar que um AVA idealizado 
para metodologias convencionais pode ser utilizado em ambientes educacionais que utilizam a metodologia PBL, mas o processo será potencializado com um ambiente online personalizado para a colaboração entre os grupos e para o estudo autônomo. Outro ponto a ser considerado no AVA refere-se aos mecanismos de interação que serão utilizados em uma abordagem dessa natureza. $A$ interação baseada em texto síncrono através da internet é muito importante para garantir o sentido de presença e para melhorar o trabalho em grupo, principalmente no que se refere ao preenchimento do Quadro Referencial. Mas é importante ressaltar que os recursos de comunicação assíncrona, sobretudo o fórum de discussão, complementam e aprofundam as discussões iniciadas no Chat. Além disso, as interações entre os alunos podem ser acompanhadas pelo professor, permitindo a ele mediar o processo de aprendizagem de modo mais pontual.

\section{CONCLUSÃO}

Os AVAs atuais fornecem muitas ferramentas colaborativas que possibilitam melhorar o fluxo de trabalho e da informação no processo da Aprendizagem Baseada em Problemas, mas ainda faltam nesses ambientes módulos específicos para gerenciar as fases do processo, ou seja, são raros os AVAs criados especialmente para atender ao paradigma do PBL. Assim, esta pesquisa, ainda em desenvolvimento, abordou o emprego do PBL-SYS, um AVA específico para apoiar o processo de resolução de problemas no PBL, enfatizando a vantagem mais significativa que o PBLSYS pode oferecer para a metodologia PBL: a aprendizagem colaborativa.

\section{REFERÊNCIAS}

ALVES-MAZZOTTI, Alda Judith; GEWANDSZNAJDER, Fernando. 0 método nas ciências naturais e sociais: pesquisa quantitativa e qualitativa, São Paulo: Pioneira, 1999.

BOGDAN, Roberto C.; BIKLEN, Sari Knopp. Investigação Qualitativa em Educação. Porto, Portugal: Porto Editora, 1994.

BRODIE, Lyn. Problem Based Learning In The Online Environment - Successfully Using Student Diversity And E-Education. In: 2006 Annual Conference on Internet Research 7.0: (IR 7.0): Internet Convergences, 27-30 Sept 2006, Brisbane, Qld, Australia. 2006. Disponível em: http://eprints.usq.edu.au/2250/1/Brodie_IR7_PV.pdf. Acesso em: 06/03/2014.

FREIRE, Paulo. Pedagogia da autonomia: saberes necessários à prática educativa. 36. ed. São Paulo-SP: Paz e Terra, 1996.

LAKATOS, Eva Maria; MARCONI, Marina de Andrade. Fundamentos da Metodologia Científica. São Paulo: Atlas, 1985. 
MARTINS, Joel. A Pesquisa Qualitativa. In: FAZENDA, Ivani (Org.). Metodologia da Pesquisa Educacional. 11a Edição. São Paulo, Cortez, 2008.

MICHALISZYN, Mário Sergio; TOMASINI, Ricardo. Pesquisa: orientações e normas para elaboração de projetos, monografias e artigos científicos. 3ạ Edição. Petrópolis, RJ: Vozes, 2007.

MORAES, M. C. Tecendo a rede, mas com que paradigma? In: Moraes, M. C. (Org.). Educação a distância: Fundamentos e práticas. OEA/MEC, Unicamp, NIED, 2002.

SEVERINO, Antônio Joaquim. Metodologia do Trabalho Científico. 23a ed. rev. e atualizada - São Paulo: Cortez, 2007. 